\title{
David Stern
}

\section{Textbook alternatives \\ Less expensive for students with possibilities for greatly enhanced pedagogy}

G iven recent online advances, the Saint Xavier University Library felt it was time to address long-standing concerns with textbook use, particularly issues of both cost and effectiveness. This article describes some recent library integration and enhancement efforts in collaboration with various campus offices that address such textbook concerns. Our grant-funded initiative will demonstrate possibilities for 1) significant reductions in student costs, 2) the creation of more interesting assignments, and 3) measurable methods to document materials use, student learning, and revisions to teaching methods after iterative querying of student comprehension.

Textbooks have been a topic of contention for quite some time, in terms of costs and best practices. This was true of paper textbooks, and it is also true for new electronic textbooks. Many faculty are dissatisfied with available textbooks. They have issues with the content, the presentation, the prescribed nature of the learning elements, and even the costs. Some faculty create reserve course packets that are composed of selected materials from various textbooks. Others simply create their own materials to replace or supplement the assigned textbooks. Students complain about the cost and the fact that many faculty only use small portions of expensive textbooks.

Regardless of the quality of the materials, many students will not or cannot purchase or lease these commercial materials. A U.S.
PIRG Education Fund study determined that $60 \%$ of students simply do not buy their required textbooks. ${ }^{1}$

Anecdotal comments from students show how little of a book may be actually used, how poorly they often explain the topics, and how few helpful visualization elements are included. Rampant scanning and copying occurs of portions of textbooks in libraries. Many libraries no longer choose to make reserve textbook copies available, and those that do buy or house a donated faculty copy find that the one copy is woefully inadequate to support the needs of many students.

In adopting commercial online textbooks, there can also be a bewildering number of options for purchase or lease, for supplementary materials and testing modules, and for perpetual long-term access. Along with these selection options can come some rather complicated login and configuration requirements. Some textbooks even require instructors to validate online users before students can gain access to their materials. Most online textbooks are not designed for organizational subsidization, due to the use of personal logins for accessing the addedvalue materials (self-help tracking, grading, etc.). Recently, in some cases where a deci-

David Stern is library director at Saint Xavier University, email: stern@sxu.edu

(C) 2017 David Stern 
sion is made to support campus subsidies of commercial solutions, new site license approaches provide ways to address these student personalization demands. Finally, not all commercial textbooks seamlessly integrate into campus CMS teaching platforms and grade books.

Given these continuing concerns with commercial textbooks and the prevalence of new online teaching options, surely it is time to reconsider the traditional textbook as the optimum teaching tool. New technologies allow for far more engaging teaching tools and methods, so let's look at some ways libraries can be involved in enhanced curriculum support scenarios. We shall also advocate for incorporating additional library elements into the curriculum to support the latest pedagogical best practices. Of course, it doesn't hurt that we may be able to significantly reduce student textbook costs in the process.

\section{Library learning objects integrated into the classroom spaces}

We have taken a two-pronged approach to advocating for textbook alternatives on our campus. We initially spent the past two years developing enhanced point-of-need help for students through a variety of learning objects. The first materials provided are a combination of 1) a text-based Scholarly Research Process Outline guide, which describes the various steps of performing indepth research, ${ }^{2}$ 2) subject-specific help pages identifying best tools based upon the type of information desired (i.e., definitions, facts, news, expert opinions and research reports, data sets, etc.), ${ }^{3}$ and 3 ) a suite of short video tutorials describing the individual steps in every stage of the discovery and information handling process. ${ }^{4}$ These resources assist students in remote settings and provide refreshers for those who want to revisit ideas described in classroom instruction visits.

The next phase of our information fluency training program is composed of targeted videos and surrounding quizzes built into our campus CANVAS learning platform.
Introductory library video tutorials and auizzes are embedded into Philosophy 140 and Philosophy 150, the courses required of all students within the General Education core curriculum. These tutorials present the basic approaches to finding types of information within customized subject pages. The tutorials highlight tools for identifying basic facts and definitions, in-depth expert information, current news, video materials, raw data, and statistics. The tutorials also describe more advanced navigation options such as citation tracking, critical thinking about quality assessment of sources, capturing information into a knowledge tool for further reflection, and the use of appropriate citations to avoid plagiarism. The quizzes test comprehension of these concepts, and a completely correct set of answers is required for passing the module. We have a very high success rate with these introductory modules, and time will tell if future papers by these students show significant improvement in selected resources and/or deeper critical thinking.

Recent additions to this orientation program include scaffolded subject-specific video tutorials and quizzes, which are embedded within higher-level undergraduate and graduate courses. These customized tutorials present the concept of communities with cultural networks and highlight specific tools and techniques for more in-depth discovery, navigation, and information-handling when using specific population resources. The quizzes test comprehension of these concepts, and a completely correct set of answers is required for passing the module. These higher-level modules are embedded within the following disciplines: the School of Education, the Graham School of Management, and the School of Nursing.

This subject-specific approach is leading to even deeper integration into other classroom and online course participation opportunities. We have developed graded assignments that demonstrate advanced critical thinking through the development of rather complex research questions. We witness sophisticated resource organization and annotation using 
the Zotero personal information software. Teaching faculty recognize the nuanced subject facets generated, and corresponding higher-level contemplation that students produce, as Zotero facilitates the capture and meta-description of materials.

One example is the categorization of materials within the topic of demonic possession into areas such as religion, language spoken, geographic region, and possible scientific explanation. The resulting paper demonstrated a thoughtful consideration of a number of alternative perspectives with a well-balanced set of supporting materials. The students were excited to see how the library tools allowed them to dig deeper into the topics, discovering new areas for exploration and contemplation.

We are planning to expand these tutorials and quizzes into other disciplines within the College of Arts and Sciences. At this time, these subjects are still addressed by classspecific web pages and site visits into classes throughout the semester, supported by the previously mentioned suite of student help tutorials found on our library website. We know identifying point-of-need resources and embedding pre-created search hedges will be even more effective for distance education and in customized settings.

One successful collaboration is in a Women in Science course, where we have embedded a number of exciting elements. We have incorporated assignment-specific materials and links that help students find the latest news, biographical information, and contextual settings for their identified person. Links exist to not just best databases, but also to pre-created searches in appropriate databases that produce the most current results for their assigned topics. We find a balance between teaching students how to search for information and providing them with the raw materials that enable them to spend more time on their actual critical analysis.

The link results quickly demonstrate the differences in perspectives that derive from intentionally broad databases (i.e., psychology, social work, science, business news, ethnic news) and Women's Studies coverages. The presentation of actual assignment-specific search results from multiple databases clearly raises the awareness of our students about the types of information that will be found based upon the initial search domain.

Our quiz results show very successful comprehension (85\%) of basic library skills and techniques, and these modules provide another early indicator of potential student problems for the General Education program. Small modifications are being made to the materials based upon student feedback, which is requested at the end of each semester during the usual course feedback process. Another benefit of this deeper library integration is the growth of more personal connections between the subject librarian and associated students and professors.

We expect that additional embedded pedagogy enhancements will occur after we demonstrate these successes at our next Faculty Professional Development Day. Such peer collaboration sessions have been responsible for our campus adoption of Zotero and the embedding of permalink journal articles into a number of courses as supplemental or replacement materials.

\section{CIDAT collaborations to enhance pedagogy ... better, measurable}

Once we established our value within classroom spaces, we became more integral within the faculty professional development program by collaborating with the Center for Instructional Design and Academic Technology (CIDAT). As the result of previous successful collaborations with CIDAT, such as building an Open Educational Resources (OER) website and support service, we were invited as partners into their online teaching certification program. The identification of appropriate library resources is now a required element in course design, and our material and librarian presences are a standard part of the pedagogy. The intention is to insert point of need materials, surrounded by leading questions and comprehension quizzes, as essential parts of best 
practices for developing an engaging pedagogy. Quizzes are more frequent, and less high stakes, which is now the accepted method of providing frequent and helpful feedback.

Within this scenario, the library not only provides supplemental support material, we now offer viable no-additional-cost alternative materials to expensive textbooks while simultaneously advocating for and supporting more interactive, customized, and measurable teaching methods.

Based upon the same pedagogical justifications, we are now promoting the use of more effective embedded resources, including both free OER and locally created alternatives to commercial textbooks. At our recent Faculty Professional Development Day, the library and CIDAT offered two sessions on embedding materials for such pedagogy enhancement. We demonstrated examples of embedded pre-created searches, database links, specific articles, and pointers to help pages.

In an important innovation, these embedded materials were preceded with leading questions for consideration as students read or watched the material.

The associated post-reading quiz questions demonstrate a number of important measurables that indicate understanding. First, there is proof of pre-class reading, as students must provide the ISBN and selected details of the material that can only be found within the material. Second, the quizzes show a basic understanding of the key concepts in the material through a set of multiple-choice and reflection questions. Third, the students must demonstrate the advanced ability to apply learned knowledge through changing-conditions questions. These last two types of post-reading questions identify common problem comprehension areas. This information can assist teachers in focusing successive flipped classroom sessions. Such feedback may also allow teachers to modify the curriculum and assignments for future classes.

An additional benefit of adopting these more interactive and testable efforts is the ability to document outcomes and impacts for upcoming Higher Learning Commission accreditation purposes.
The library has become an important player in crafting and supporting new teaching methods that provide a more customized, exciting, and effective approach. Oh, and did I already mention that such an approach can also save significant dollars when addressing expensive textbooks?

\section{Costs}

The final step is to combine our efforts to enhance the pedagogy with our interest in reducing student costs. It may be possible in many circumstances to replace commercial textbooks with freely available OER, already purchased leased library materials, or locally created materials.

The library had an earlier 2009 Department of Education "College Course Materials Rental Initiative" grant intended to help students find less expensive ways to purchase and lease textbooks. This fund was redirected to alternative approaches after the bookstore was purchased by a commercial company. In this new scenario, we have elected to repurpose our textbook support grant toward new strategic approaches. The library coordinates an effort to develop a campus infrastructure that raises the awareness of such opportunities. We also work with CIDAT to support faculty explorations of appropriate options, and provide hardware, software, and staff assistance in developing local alternatives or supplemental material.

We have already used our funding to explore a variety of options.

1. We provided a faculty summer stipend to compare and contrast the effectiveness of various commercial ebook platforms.

2. We provided a faculty summer stipend to develop iPad teaching modules that would replace a textbook within our one-to-one nursing personal assistant tool initiative.

3. We hired students to explore, describe, and facilitate the discovery of available OER materials.

4. We collaborated on a section of the CIDAT Faculty Toolkit that encourages faculty to adopt existing OER materials.

5. We purchased hardware and software to assist faculty in developing local materials. 
6. We are building an online clearinghouse for locally developed materials and approaches.

7. We are planning for a series of faculty fairs to showcase demonstrations (showing peer products is far more effective than explaining theoretical possibilities).

We will soon start to post to our campus website a running total of savings generated from our adoption of alternatives to commercial textbooks. We also hope to include testimonials from students about the improved teaching environment we have created.

Highlighting cost savings to students and enhanced pedagogy benefits for students and faculty is a great way to more deeply integrate the library into the evolving campus teaching enterprise. Using textbook alternatives is a great way to start these conversations.

\section{Notes}

1. Www.uspirg.org/sites/pirg/files / r e ports / N A T I O N A L \% 20 Fixing \%20Broken\%20Textbooks\%20Report1.pdf.

2. http://sxu.beta.libguides.com /scholarlyresearch.

3. See business example at http://lib.sxu.edu /businessdatabases.

4. The Quick Tutorials can be found at http://lib.sxu.edu/undergraduates. $\boldsymbol{n}$

("What about the bookstore?" continues from page 377)

to cooperation. Acknowledging our points of contention or mistrust could serve as the basis of an initial discussion between the library and store to discover the path to establishing a better relationship.

\section{Take the next steps}

Academic librarians contemplating how to begin promoting textbook affordability solutions on their campus may be expecting questions about its impact on the bookstore -or possibly pushback from the bookstore. Anticipating that possibility is wise, as it will better position librarians to respond. First consider organizing an institutional working group to explore the issue of textbook affordability, if no such committee already exists. ${ }^{2}$ Make that first step and reach out to the store manager. Explain what you intend to do and why. Offer examples from other institutions that are achieving textbook affordability, and reinforce that these efforts contribute to student success. Whether your campus store is an independent or contract-managed operation may be less consequential than the attitude and spirit of your store manager. What does matter is the librarian's ability to establish where the common ground exists and to appeal to that individual's commitment to students' academic success.

When it comes to having conversations with the bookstore about textbook afford- ability, I am reminded of the bookstore manager who explained, colorfully, why he supported these programs. He reminded his colleagues that every student who dropped out owing to their inability to afford higher education, who failed courses and quit because they couldn't afford their textbooks, was one more student who would never make a purchase at the bookstore. He argued that if textbook affordability programs helped to retain at-risk and other students, that meant more customers for the store. When you look at it that way, academic libraries and bookstores, working together for student success, is a relationship that makes a lot of sense.

\section{Notes}

1. Steven J. Bell, "Coming in the Back Door: Leveraging Open Textbooks to Promote Scholarly Communications on Campus," Journal of Librarianship and Scholarly Communication 1, no. 1 (2012), DOI: http://doi. org/10.7710/2162-3309.1040.

2. Steven J. Bell, "Five Institutional Strategies for Textbook Affordability," Library Journal (February 4, 2016), http://lj.libraryjournal. com/2016/02/opinion/steven-bell/five-institutional-strategies-for-textbook-affordabilityfrom-the-bell-tower/ (retrieved February 9, 2017). n 